\title{
EN LA PENUMBRA: INDETERMINACIÓN, DERROTABILIDAD Y APLICACIÓN JUDICIAL DE NORMAS
}

\author{
Ángeles Ródenas \\ Universidad de Alicante
}

\section{Introducción}

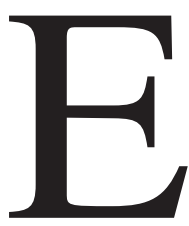

1 objeto de este trabajo es el análisis de dos conceptos vinculados con lo que, utilizando la terminología de Hart, podríamos denominar «los intersticios del Derecho», es decir, esa zona del Derecho donde la clásica división entre actos de creación y de aplicación del Derecho se desdibuja. Se trata de los conceptos de indeterminación y derrotabilidad. A mi juicio, sólo a partir de una reconstrucción cuidadosa de estos conceptos resulta posible comenzar a abordar la polémica cuestión de la creación judicial de Derecho. Dicha reconstrucción debe comenzar constatando una dificultad obvia: no hablamos de indeterminación o de derrotabilidad en un único sentido, sino que, en el uso corriente de los teóricos, estas expresiones se emplean con diversas acepciones. En las páginas que siguen me propongo explorar aquellas acepciones que me parecen más significativas, así como poner de manifiesto la vinculación que existiría entre alguno de los sentidos de indeterminación y de derrotabilidad. Mi tesis es que no es posible llegar a una comprensión completa de la indeterminación del Derecho sin una comprensión adecuada del problema de la derrotabilidad de las normas jurídicas.

Por otro lado, el análisis de los conceptos de indeterminación y derrotabilidad me permitirá extraer algunas consecuencias interesantes respecto de dos momentos fundamentales en la tarea aplicativa de normas que llevan a cabo básicamente los jueces y tribunales: la actividad interpretativa y la creación discrecional de Derecho'. A partir de los diferentes sentidos de indetermina-

\footnotetext{
${ }^{1}$ La noción de discrecionalidad que voy a manejar aquí está asociada, por lo tanto, a los problemas de indeterminación del Derecho. La discrecionalidad, así entendida, es -como se verá- un remedio ante una situación anormal que se produce en el ordenamiento jurídico: La ausencia de estándares jurídicos de acuerdo con los cuales resolver las disputas. Pero -como recientemente se ha ocupado de distinguir Isabel Lifante- la discrecionalidad se puede enten-
} 
ción y derrotabilidad voy a tratar de identificar de forma más o menos genérica los problemas de indeterminación a los que es posible poner remedio mediante la actividad interpretativa y aquellos otros ante los cuales, en cambio, no cabe sino la discrecionalidad. Mi intención es mostrar cómo, a la hora de reconstruir racionalmente la actividad aplicativa de normas que llevan a cabo los jueces y tribunales, las convenciones interpretativas desempeñarían un papel mucho más amplio del que usualmente se les atribuye, lo que no es óbice para que, de forma genérica, podamos perfilar los rasgos teóricos de aquellas situaciones de inflexión en las que la actividad interpretativa cede el paso a la creación discrecional de Derecho. Aunque la creación discrecional de Derecho sea, en mi opinión, un fenómeno bastante marginal, la interpretación no puede considerarse, en contra de como parece presentarse, una actividad que «traspasa uno y otro lado de la división entre la identificación del Derecho existente y la creación de nuevo Derecho»². Por el contrario, como acabo de señalar, por más que la interpretación se entienda como una actividad con un amplio abanico de posibilidades de juego, cabe concebir un punto en el que la baraja queda rota y no se puede seguir hablando de actividad interpretativa, sino de creación discrecional de Derecho. Proyectar un haz de luz sobre este punto de inflexión va a ser, precisamente, el otro objetivo de este trabajo.

\section{Indeterminación}

Aunque, como vamos a ver, los términos indeterminación y derrotabilidad están estrechamente ligados entre sí, es usual utilizar el término indeterminación en referencia a una característica del Derecho, mientras que se habla de derrotabilidad en relación a una cualidad de las normas jurídicas. De la indeterminación del Derecho se puede hablar en varios sentidos diferentes. Sin pretensión de exhaustividad, ni de trazar categorías necesaria-

\footnotetext{
der también en un sentido diferente, aunque relacionado con el anterior. En esta segunda acepción la discrecionalidad sería una actividad de desarrollo y concreción del Derecho, resultado de una delegación de poderes, en la que el Derecho señala los fines a alcanzar y deja en manos del operador jurídico la determinación de los medios más idóneos para ello [Cfr. «Sobre el concepto de discrecionalidad jurídica», cito por el original policopiado]. Tradicionalmente se ha entendido que el primer tipo de discrecionalidad sería la atribuida a los órganos judiciales, mientras que el segundo a los administrativos. Aunque esta contraposición resulta relativa, ya que ambas clases de órganos pueden ejercer discrecionalidad en los dos sentidos, sigue siendo válida si se la considera como una mera caracterización de las actividades desarrolladas típica o centralmente por una y otra clase de órganos.

${ }^{2}$ Cfr. RAZ, Joseph, «¿Por qué interpretar?», Isonomía, México, núm. 5, 1996, pág. 26. «En lo que a la interpretación se refiere [prosigue Raz] esta distinción no se aplica. Ya sea que algunas veces identifiquen el Derecho tal como es y otras veces hagan nuevo Derecho, los tribunales, parece ser, siempre lo interpretan».
} 
mente excluyentes entre sí, este podría ser un buen panorama de los principales sentidos en los que comúnmente se habla de problemas de indeterminación del Derecho ${ }^{3}$ :

\section{1) Indeterminación «causal» de las decisiones judiciales}

La indeterminación equivale en esta acepción a la insuficiente fuerza motivadora de las normas jurídicas en relación con las decisiones judiciales ${ }^{4}$; lo que desde esta perspectiva se cuestiona es la incidencia causal de las normas jurídicas en el razonamiento de los jueces (así como de otros aplicadores del Derecho) a la hora de adoptar decisiones. Este es el planteamiento característico del realismo jurídico americano que, como es de sobra conocido, mantiene una actitud escéptica en relación a la capacidad de las reglas para hacer derivar respuestas jurídicas determinadas. Se trata, por lo tanto, de una tesis relativa al contexto de descubrimiento de las decisiones judiciales, cuyo examen y discusión detallado requeriría contar con instrumentos de análisis procedentes de disciplinas como la sociología o la psicología. No va a ser esta la noción de indeterminación de la que me voy a ocupar en el resto del trabajo, ya que, como se verá, mi interés se centra en el contexto de justificación de las decisiones judiciales.

\section{2) Indeterminación debida a defectos lógicos de los sistemas jurídicos}

Si el estudio de los problemas asociados a la indeterminación del Derecho en la acepción que acabamos de contemplar -indeterminación causal de las decisiones judiciales- supone situarse en el contexto de descubrimiento de las decisiones judiciales, el análisis de la indeterminación debida a defectos lógicos presupone un enfoque del Derecho completamente distinto al anterior: El Derecho es visto en tanto que sistema normativo orientado a la justificación de decisiones, que se entienden justificadas en tanto su contenido resulte deductivamente derivable del contenido de normas generales (más la descripción de los hechos del caso). Por lo tanto, la indeterminación en esta acepción afecta a cuestiones de regulación o calificación deóntica. El Derecho resulta indeterminado porque no podemos precisar exactamente cuál es el estatus jurídico de determinadas acciones ${ }^{5}$. Esta indetermina-

\footnotetext{
${ }^{3}$ Trazo esta panorámica sobre los problemas de indeterminación del Derecho inspirándome básicamente tres enfoques diferentes: El de Josep Aguiló, en Teoría general de las fuentes del Derecho (y del orden jurídico), Ariel, Barcelona, 2000, pág. 108; el de Riccardo Guastini, en Le fonti del Diritto e l'interpretazione, Giufrè, Milán, 1993, págs. 345 a 357 y el de Mª Cristina Redondo, en «Teorías del Derecho e indeterminación normativa», Doxa. Cuadernos de Filosofía del Derecho, Alicante, núm. 20, 1997, págs. 177 a 196.

${ }^{4}$ Cfr. Ma . C. Redondo, ob. cit., pág. 179.

${ }^{5}$ Cfr. Ma . C. Redondo, ob. cit., pág. 108.
} 
ción puede tener su causa bien en problemas de consistencia de los sistemas jurídicos, bien en problemas de completitud. Desde esta perspectiva interesa el problema de las lagunas (normativas) y el de la inconsistencia normativa. Siguiendo a Alchourrón y Bulygin, hablamos de lagunas (normativas) cuando a un caso definido en términos de las propiedades que han sido consideradas relevantes por la autoridad normativa, no se le ha correlacionado solución normativa alguna ${ }^{6}$. Por otra parte, como es sabido, estamos ante una inconsistencia o antinomia, cuando dos o más normas del sistema jurídico atribuyen a un mismo caso soluciones normativas incompatibles ente sí.

\section{3) Indeterminación lingüística del Derecho}

Conforme a esta tercera acepción, la indeterminación supone que puede haber casos en los que no es posible identificar qué es lo que el Derecho requiere debido a problemas del lenguaje mediante el que éste se expresa. La indeterminación lingüística puede tener su origen tanto en problemas de ambigüedad como en problemas de vaguedad.

\section{1.) Problemas de ambigüedad}

La ambigüedad, puede tener su origen en alguno de los siguientes tipos de problemas: semánticos, sintácticos y pragmáticos ${ }^{7}$. Como es sabido, la ambigüedad semántica afecta a los términos. Hablamos de ambigüedad semántica cuando un mismo término es susceptible de asumir diferentes significados. Por ejemplo, en el enunciado que reconoce el derecho a la inmunidad parlamentaria de los diputados, el término diputado puede referirse sólo a los diputados en las Cortes Generales -como parece que en principio era el caso en Derecho español- o bien también a los diputados de los distintos parlamentos autonómicos o del europeo. Por su parte, la ambigüedad sintáctica afectaría a la estructura lógica de los enunciados, es decir, al modo en que las palabras están conectadas entre sí. Así, en el enunciado que expresa «podrán matricularse en la facultad de Derecho aquellos alumnos procedentes de bachillerato que hayan aprobado la selectividad y los mayores de 25 años que hayan superado las pruebas de acceso» la subordinada de relativo «que hayan superado las pruebas de acceso» puede referirse sólo a los mayores de 25 años o también a los estudiantes procedentes de bachillerato que hayan aprobado la selectividad. Finalmente, respecto de la ambigüedad pragmática, hay que comenzar advirtiendo que es un tipo de

\footnotetext{
${ }^{6}$ Introducción a la metodología de las ciencias jurídicas y sociales, Astrea, Buenos Aires, 1974, pág. 49.

${ }^{7}$ Cfr. R. Guastini, ob. cit., págs. 351 a 355.
} 
ambigüedad raro. Se produciría cuando un mismo enunciado puede cumplir diferentes usos o funciones del lenguaje, sin que del contexto sea posible esclarecer de qué uso se trata. Por ejemplo «corresponde al Decano convocar la Junta de Facultad» podría entenderse como el establecimiento de una condición necesaria y/o suficiente para la convocatoria de la Junta de Facultad, o bien como una norma de mandato que obliga al Decano a convocar la Junta de Facultad.

\section{2) Problemas de vaguedad}

Como es de sobra conocido, la vaguedad no afecta a los términos, sino a los conceptos. Es posible diferenciar entre problemas de vaguedad extensional y de vaguedad intensional. Hablamos de vaguedad extensional cuando no está claro el campo de aplicación de un concepto y de vaguedad intensional cuando no quedan claros el conjunto de rasgos que lo caracterizan. Por ejemplo, en el enunciado que expresa «se considerará punible la tenencia de droga en cantidad suficiente para el tráfico», la noción de «cantidad suficiente para el tráfico» resulta intensionalmente vaga. ¿Dónde situar el límite entre una cantidad de droga destinada al consumo y una cantidad destinada al tráfico? ¿Son 100 gr. de hachís una cantidad de droga destinada al consumo? ¿Y 110? ¿Y 150?...

Ahora bien, los problemas de vaguedad no sólo se producen por un debate estrictamente semántico, sino que también pueden deberse a un debate valorativo ${ }^{8}$. Para ilustrar este tipo de imprecisiones voy a traer a colación la célebre distinción de Dworkin entre conceptos meramente vagos, que revelan la existencia de dificultades puramente semánticas -como sucedía en el caso de «droga destinada al consumo», y conceptos interpretativos, que tienen su origen en desacuerdos de carácter político y moral y que dan lugar a lo que Dworkin llama «conflictos interpretativos» ${ }^{9}$. Esto es lo que sucede, por ejemplo, con el concepto de «trato inhumano o degradante» al que alude la Constitución española ${ }^{10}$.

\footnotetext{
${ }^{8}$ Cfr. M $M^{\text {a }}$.C. Redondo, ob. cit., pág. 182.

${ }^{9}$ Cfr. Ronald Dworkin, A matter of principle, Harvard University Press, Cambridge, 1985, pág. 128; Law's Empire, Belknap Press, Harvard, 1986, pág. 702; Los Derechos en serio, trad. de Marta Guastavino, Ariel, Barcelona, 1989, pág. 214.

${ }^{10}$ Aunque esta última categoría también se puede considerar incluida en la anterior. Así Cristina Redondo subraya que «los conceptos que admiten varias interpretaciones están necesariamente ligados a los problemas de vaguedad» [cfr. ob. cit., pág. 188].

En Ilícitos atípicos Manuel Atienza y Juan Ruiz Manero han subrayado que lo que los juristas llaman «conceptos jurídicos indeterminados» son conceptos que califican valorativamente una cierta conducta o estado de cosas sin determinar, en términos de propiedades descriptivas, cuáles sean sus condiciones de aplicación, y que ésta es la razón de que su aplicabilidad concreta resulte controvertible en la mayoría de los casos. [cfr.ATIENZA, Manuel y RUIZ MANERO, Juan, Ilícitos atípicos, Trotta, Madrid, 2000, pág. 41 n. 5].
} 


\section{4) Indeterminación debida a problemas de coherencia normativa}

\section{o congruencia}

Esta última acepción está asociada a la noción de derrotabilidad de las normas jurídicas de la que pasaré a ocuparme en el siguiente apartado. Por el momento, me interesa señalar que el análisis de los problemas de indeterminación del Derecho desde esta última perspectiva supone considerar el Derecho desde una óptica completamente diferente a las anteriores. Lo decisivo aquí es contemplar el Derecho no sólo en su función guía unitaria de la conducta, es decir, como un mecanismo para el establecimiento unívoco de cuáles son nuestros deberes, sino, sobre todo, como una forma de protección de un cierto sistema de bienes o valores jurídicos. Es en este último contexto en el que cobra sentido la idea de coherencia, entendida como un planteamiento sobre la compatibilidad entre los diferentes fines o valores que el Derecho incorpora ${ }^{11}$. Proporcionar un cuadro de los supuestos genéricos en los que tales conflictos pueden producirse es extraordinariamente complejo, aunque en el siguiente epígrafe -al hilo del análisis de la noción de derrotabilidad- voy a aventurar alguna propuesta en este sentido. Por el momento, basta con señalar que la superación del conflicto entre diversos

${ }^{11}$ No creo estar sosteniendo aquí nada muy diferente a lo ya apuntado por Josep Aguiló en Teoría general de las fuentes del Derecho, ob. cit., pág. 96.

Desde un enfoque diferente al que voy a desplegar en las páginas siguientes, Jorge Luis Rodríguez ha perfilado un concepto de laguna axiológica que, en una de sus acepciones, podría proporcionar un buen punto de partida para un análisis alternativo al que aquí se expone -aunque no necesariamente incompatible con él-. Este autor defiende que «bajo el concepto de laguna axiológica parecen confundirse dos nociones diferentes: La idea de laguna axiológica como enunciado de crítica respecto de un sistema normativo (un enunciado prescriptivo) expresado desde el punto de vista interno de otro sistema normativo (el sistema axiológico del intérprete), y la idea de laguna axiológica como enunciado interpretativo respecto de cierto conjunto de formulaciones normativas que intenta reconstruir las intenciones de la autoridad normativa. En este segundo sentido, no se trata necesariamente de un enunciado prescriptivo o valorativo, dado que puede tratarse simplemente de una descripción del hecho de que, aunque la autoridad normativa no le ha atribuido relevancia a una cierta propiedad a través de una formulación explícita, esa propiedad es implícitamente relevante en el sistema de acuerdo con el sistema axiológico presupuesto por la autoridad, el cual puede ser reconstruido a través de un análisis cuidadoso de las restantes normas promulgadas por la autoridad [Cfr. Jorge Luis Rodríguez, Lagunas axiológicas y relevancia normativa», Doxa. Cuadernos de filosofía del Derecho, Alicante, 1999, núm. 22, págs. 349 a 369 (la cursiva es mía)].

Análogamente, Manuel Atienza y Juan Ruiz Manero han elaborado el concepto de laguna axiológica en el nivel de las reglas, que definen así: «Un cierto caso constituye una laguna en el nivel de las reglas de un cierto sistema jurídico, si las reglas de ese sistema jurídico solucionan el caso, pero sin que dichas reglas consideren como relevante para esa solución una cierta propiedad que, de acuerdo con la hipótesis de relevancia derivada de los principios de ese sistema jurídico, sí debiera considerarse como relevante» (p. 62). Las figuras del abuso del derecho, del fraude de ley y de las desviación de poder, serían, a juicio de estos autores, otros tantos remedios para supuestos distintos de lagunas axiológicas en el nivel de las reglas. 
valores jurídicos requiere la realización de ponderaciones o balances entre las diferentes razones que el Derecho incorpora. Cómo y hasta qué punto las convenciones interpretativas proporcionan una guía útil para ello es una cuestión que dependerá de la concepción del Derecho de la que se parta.

Antes de proseguir conviene reparar en que los problemas de vaguedad debidos a imprecisiones valorativas -a los que he hecho alusión- y los problemas de coherencia normativa que ahora nos ocupan, pueden solaparse -y de hecho con frecuencia así sucede- . Dicho en otros términos, la vaguedad debida a imprecisiones valorativas puede revelar un conflicto entre planteamientos incompatibles en relación a los valores y fines que el Derecho incorpora. En tal caso estaríamos ante dos formas alternativas de presentar un mismo problema de indeterminación: en el primer caso la indeterminación se presenta como un problema lingüístico (debido a un conflicto valorativo), mientras que en el segundo como un problema de coherencia normativa. No obstante lo dicho, me parece que conceptualmente es interesante mantener la distinción y ello fundamentalmente por una doble índole de razones: Para empezar, creo que es preferible hablar de problemas de coherencia para hacer alusión aquellos conflictos entre planteamientos relativos a los valores y fines que el Derecho incorpora que -como en breve veremos- sólo es posible saldar con la derrota de alguna norma del sistema. Por lo tanto, las imprecisiones debidas a problemas de coherencia normativa estarían indisociablemente unidas a la derrotabilidad de las normas, a diferencia de las valorativas, que presuponen un conflicto entre concepciones de carácter político y moral y no necesariamente entre normas del sistema. Pero, sobre todo, creo que es importante mantener esta distinción puesto que -como también vamos a ver- es perfectamente posible hablar de indeterminación del Derecho debida a problemas de coherencia normativa sin que los términos contenidos en las normas adolezcan de ningún tipo de vaguedad conceptual (al menos tal y como ésta ha sido aquí definida).

\section{Derrotabilidad}

Como sostenía al comienzo, la derrotabilidad es una característica que suele predicarse de las normas jurídicas y no tanto del Derecho ${ }^{12}$. Creo que

\footnotetext{
${ }^{12}$ En este mismo volumen Juan Carlos Bayón analiza y critica cuatro argumentos a favor de la derrotabilidad del razonamiento jurídico, asociados a otras tantas causas o sentidos de «derrotabilidad». Estos argumentos, que estarían relacionados en mayor o menor medida entre sí, atribuyen respectivamente la derrotabilidad del razonamiento jurídico: a la pragmática de los procedimientos jurídicos; al conocimiento incompleto de los hechos o del Derecho; a necesidades derivadas del tratamiento de las excepciones en la representación del conocimiento jurídico y, en fin, a la derrotabilidad misma de las normas jurídicas. Este último argumento sostiene que la derrotabilidad de las normas jurídicas es una consecuencia de la interacción entre reglas y principios. La tesis podría resumirse de forma muy concisa de la siguiente
} 
la mejor forma de dar cuenta del problema de la derrotabilidad de las normas jurídicas es traer a colación aquí el papel que las mismas juegan en tanto que razones para la acción, aunque ello me obligará desviarme brevemente del objeto central de este trabajo. Como es sabido, una de las principales contribuciones de Raz a la teoría del Derecho es su análisis de las normas en términos de razones para la acción ${ }^{13}$. El punto de partida de dicho análisis es la consideración de las reglas como la expresión de un compromiso entre razones de primer orden. Tener una regla significa que, cuando se producen las condiciones para su aplicación, no componemos un nuevo balance con todas las razones de primer orden aplicables al caso, pues la decisión ya está tomada de antemano. Partiendo de este presupuesto, Raz caracteriza las normas jurídicas como razones protegidas para la acción. Centrándonos en el razonamiento judicial, que es el que ahora nos ocupa, caracterizar a las normas jurídicas como razones protegidas significa simultáneamente dos cosas: que la regla constituye para el juez una razón de primer orden para realizar la acción exigida, es decir, para dictar una resolución cuyo contenido se corresponda con el de la regla, y, a su vez, que la regla es también una razón excluyente para prescindir del resultado al que llevaría una deliberación independiente por parte del juez sobre los argumentos en pro y en contra de realizar la acción, es decir, una razón para excluir que el contenido de la resolución se fundamente en la apreciación por parte del órgano jurisdiccional de cuál fuera, atendiendo a los méritos del caso, la mejor resolución a dictar.

¿Cómo pueden las normas, caracterizadas en los términos que acabamos de ver, ser derrotables?. Parece que su carácter, en tanto que razones protegidas, excluye el rasgo de la derrotabilidad. Algunos autores, como Juan Carlos Bayón, han resuelto esta cuestión renunciando a la idea de que las

manera: «Dado que no es posible precisar de antemano en qué casos genéricos prevalecerá un principio sobre otros y que cualquier regla está sujeta a excepciones implícitas por razones de principio (lo que nos reconduciría de un modo u otro a un balance entre principios), toda norma jurídica, ya sea un principio o una regla, tendrá excepciones implícitas que no es posible identificar genéricamente por anticipado Cfr. Bayón Mohíno, Juan Carlos, “¿Por qué es derrotable el razonamiento jurídico?"», Doxa, n 24, 2001, pp. 35-62.

Es de este último argumento a favor de la derrotabilidad del que me voy a ocupar aquí. Ahora bien, como pronto se verá, creo que cuando se habla de derrotabilidad de las normas jurídicas no hay una única acepción en juego, sino al menos tres. Me parece importante destacar este hecho, porque puede ayudar a descartar inútiles pseudo polémicas basadas en un uso no unívoco del concepto y a redefinir la verdadera dimensión de los genuinos desacuerdos sobre el carácter derrotable o no de las normas jurídicas -fundados en último extremo en diferentes concepciones del Derecho y de la subsiguiente capacidad de éste para resolver ciertos problemas de indeterminación-.

${ }^{13}$ Cfr. Razón práctica y normas, trad. de Juan Ruiz Manero, Centro de Estudios Constitucionales, Madrid, 1991. 
normas sean razones protegidas para la acción y caracterizándolas como meras razones de primer orden para actuar. Razones de primer orden que, en tanto tales, deben ser ponderadas por el juez junto con cualesquiera otras razones de primer orden que sean aplicables para la resolución del caso en cuestión ${ }^{14}$.

Ahora bien, otros autores no han considerado el problema de la derrotabilidad como un obstáculo insubsanable que, por lo tanto, lleve aparejado inexorablemente el abandono de la caracterización de las reglas en tanto que razones protegidas. Este es el caso de Atienza y Ruiz Manero, quienes en Las piezas del Derecho se valen precisamente de la caracterización de las reglas como razones protegidas ${ }^{15}$ para perfilar, a mi juicio de forma bastante esclarecedora, la distinción entre reglas y principios. Para estos autores las reglas estarían destinadas a que, cuando se dan sus condiciones de aplicación, los órganos primarios excluyan, en cuanto base de su resolución, su propio juicio acerca del balance de razones aplicables y adopten como tal base el contenido de la regla. Por su parte, los principios no constituirían para Atienza y Ruiz Manero razones perentorias o protegidas, ya que no están destinados a excluir la deliberación por parte del órgano jurisdiccional acerca del contenido de la resolución a dictar, sino que constituyen meramente razones de primer orden para resolver el caso de que se trate en un determinado sentido. Como razones de primer orden su fuerza respecto de otras razones para resolver el caso en otro sentido -por ejemplo, otros principiosha de ser ponderada por el propio órgano jurisdiccional.

Así, por ejemplo, la diferencia entre el principio que prohíbe la discriminación por razón de sexo, y la regla que establece la obligación de pagar un salario igual a hombres y mujeres estaría en que, cuando es aplicable la regla a un supuesto de hecho, el órgano jurisdiccional debe abstenerse de realizar una deliberación sobre el contenido de la resolución a dictar y aplicar la solución normativa estipulada en la regla. En cambio, del mero hecho de que a un supuesto de hecho le sea aplicable el principio de prohibición de la discriminación por razón de sexo sólo se infiere que hay una razón para no discriminar, pero no una solución normativa para el caso, ya que esta razón tendrá que ser ponderada con cualesquiera otras razones que sean también aplicables al supuesto ${ }^{16}$.

${ }^{14}$ Cfr. J. C. Bayón, «Sobre la racionalidad de dictar y seguir reglas», Doxa. Cuadernos de Filosofía del Derecho, Alicante, núm. 19, 1997, págs. 143 a 180.

15 Aunque estos autores, adoptando la conocida terminología del último Hart, prefieren hablar de las reglas jurídicas de mandato como razones perentorias para la acción, la noción de razón perentoria viene a coincidir con la de razón protegida de Raz a la que acabo de referirme.

${ }^{16}$ La caracterización de los principios en términos de razones de primer orden para la acción tiene importantes consecuencias de cara a los aspectos normativos del razonamiento jurí- 
Pero, aunque los jueces, en la mayoría de casos, adoptan como base de su resolución reglas jurídicas preexistentes, en tanto que razones perentorias, sabemos que también hay casos excepcionales en los que dejan de lado las reglas aplicables. Es aquí precisamente donde entra en juego la noción de derrotabilidad de las reglas. Dicho en otros términos, hablamos de derrotabilidad cuando las reglas dejan de ser tomadas como razones excluyentes en la base de la deliberación judicial. De manera que hasta aquí no hemos avanzado demasiado ya que, aunque la noción de razón protegida nos permite captar la distinción entre reglas y principios, todavía no hemos afrontado el problema de la incompatibilidad entre el carácter de razón protegida de las reglas y la derrotabilidad de las mismas. Tratar de contestar a esta cuestión no es nada simple, ya que, como pretendo mostrar, no hay una única noción de derrotabilidad en juego, sino varias.

Para dar cuenta de las distintas acepciones del término derrotabilidad, empezaré por introducir una distinción bien conocida que aquí va a ser crucial. Se trata de la distinción entre las justificaciones subyacentes a la regla y las prescripciones contenidas en la formulación normativa de la regla. Por ejemplo, pensemos en una señal que prohíbe los aparatos de radio en la biblioteca universitaria: La señal podría haberse colocado debido a la molestia que ocasiona a los usuarios de la biblioteca el ruido de dichos aparatos. El juicio de que tal razón viene a prevalecer frente a la constituida por el deseo de algunos usuarios de escuchar la radio en la biblioteca vendría a ser la justificación subyacente a la regla. En todo caso, si interrogamos a la señal, lo único que ésta nos dice es que están prohibidos los aparatos de radio en la biblioteca (prescripción contenida en la formulación normativa de la regla). Siguiendo a Frederick Schauer, podemos entender las prescripciones contenidas en las formulaciones normativas como generalizaciones que tratan de ejemplificar el resultado que normalmente podría obtenerse de la aplicación directa de las justificaciones (no ocasionar molestias a los usuarios de la biblioteca) ${ }^{17}$. Pues bien, podemos afirmar que las formulaciones normativas poseen autonomía semántica, esto es, que su significado -lo que las mismas prescriben- puede establecerse sin tomar en cuenta la justifica-

\footnotetext{
dico justificativo. Desde esta perspectiva Atienza y Ruiz Manero han señalado, entre otras cosas, que los principios, «[p]or un lado, no presentan las ventajas de las reglas, pues no permiten ahorrar tiempo a la hora de decidir un curso de acción. Pues si una regla es aceptada y ella es aplicable al caso que nos ocupa, entonces se evita tener que entrar en un proceso de ponderación de razones en pro y en contra de una determinada decisión; la regla opera, por tanto, como un elemento que reduce la complejidad de los procesos de argumentación. Sin embargo, los principios -como se ha visto- no eximen de la tarea de efectuar esa ponderación. Por otro lado, los principios, en cuanto premisas a utilizar en los argumentos prácticos, tienen menos fuerza, son menos concluyentes que las reglas» [Cfr. Las piezas del Derecho, ob. cit., pág. 13 y 21].

${ }^{17}$ Cfr. Frederick Schauer, Playing by the Rules, Oxford Clarendon Press, 1991.
} 
ción que subyace a las mismas. Así, yo soy capaz de atribuir significado a la señal que prohibe los aparatos de radio en la biblioteca, aunque desconozca cuál es la justificación subyacente a esta disposición. Esta autonomía semántica de las formulaciones normativas puede dar lugar a que en algunos casos se produzca un desajuste entre aquello que la formulación normativa nos exige y lo que la justificación subyacente a la misma requiere. Este tipo de experiencias son conocidas como experiencias recalcitrantes y pueden revestir dos formas: Cabe que, en ciertos casos particulares, la generalización contenida en la formulación normativa comprenda estados de cosas que no produzcan la consecuencia representada en la justificación de la regla. Volviendo al ejemplo de la señal que prohibe los aparatos de radio en la biblioteca, es fácil concebir supuestos en los que la justificación subyacente a esta regla no sería aplicable: el empleado que limpia la biblioteca antes de la hora de apertura al público; la bibliotecaria que, ante una alarma de inundaciones, está pendiente de un aviso de protección civil para evacuar la biblioteca, etc. Decimos que en estos casos la prescripción contenida en la formulación normativa es supraincluyente en relación con su justificación subyacente, en el sentido de que tal prescripción incorpora ciertos supuestos -el del empleado de la limpieza o el de la bibliotecaria- en los que no sería aplicable su justificación. En cambio, la prescripción contenida en la formulación normativa es infraincluyente cuando no comprende ciertos estados de cosas que pueden contribuir, en casos particulares, a la consecuencia representada en la justificación subyacente a la regla, es decir, cuando las prescripciones contenidas en las formulaciones normativas no incorporan ciertos supuestos en los que su justificación sí sería aplicable. Por ejemplo, la prohibición de aparatos de radio no afecta a los reproductores de audio, televisores, etc., pero, sin embargo, parece claro que su utilización causaría molestias análogas a los usuarios de la biblioteca.

Vamos a detenernos por unos instantes en las experiencias recalcitrantes ocasionadas por el carácter supraincluyente de las prescripciones contenidas en las formulaciones normativas, ya que, profundizando algo más en este fenómeno, podremos trazar una aproximación a la primera de las nociones de derrotabilidad de las que me voy a ocupar. En otro lugar he diferenciado dos tipos de supuestos que ilustran perfectamente este género de experiencias recalcitrantes. Se trata de los supuestos que quedan fuera del alcance de una regla y de aquellos que constituyen una excepción a la mis$\mathrm{ma}^{18}$. Empecemos por los primeros. Decimos que un caso está fuera del al-

${ }^{18}$ Razonamiento judicial y reglas, Fontamara, México D.F, 2000. He desarrollado estas categorías a partir de una distinción que Raz realiza en Razón práctica y normas, ob. cit, pág. 82. 
cance de una regla si las principales razones que respaldan la regla no son aplicables a tal caso. Si volvemos nuevamente al ejemplo de la prohibición de aparatos de radio en la biblioteca, el supuesto del empleado de la limpieza que conecta la radio antes de la hora de apertura al público podría considerarse como un caso fuera del alcance de la regla, ya que la acción del empleado no causa molestias a los usuarios de la biblioteca.

En cambio, un caso cae bajo una excepción a la regla cuando le es aplicable algunas de las principales razones en pro de la regla, pero hay otras razones presentes que no han sido tenidas en cuenta en el balance de razones que la regla contempla. Así, en el caso de la bibliotecaria que conecta la radio pendiente de un aviso de protección civil, podríamos entender que estamos en presencia de una excepción a la regla, ya que ciertamente la acción de la bibliotecaria produce molestias a los usuarios de la biblioteca, lo que sucede es que se considera que la información de la que está pendiente la bibliotecaria es vital de cara a abortar el peligro para la vida de las personas que están en la biblioteca y que esta última razón, el valor de la vida humana, prevalece sobre aquellas otras contempladas en el compromiso (o juicio de prevalencia) expresado en la regla. Dicho de otro modo, lo que la regla contempla es simplemente que la tranquilidad de los usuarios de la biblioteca (razón 1) prevalece frente al deseo de algunos usuarios de oír la radio (razón 2), pero no frente al valor de la vida humana (razón 3).

Como se advierte en los ejemplos anteriores, tanto en los supuestos de excepción a las reglas, como los casos fuera del alcance de las mismas, se produce la derrotabilidad de las prescripciones contenidas en las formulaciones normativas, pero no del balance de razones subyacente a las mismas. Esto es así debido a que las cuestiones relativas al alcance y a las excepciones a las reglas pueden resolverse sin reabrir el balance de razones subyacentes. El vigilante que no impide al empleado de la limpieza o a la bibliotecaria oír la radio no necesariamente vuelve a realizar un balance con todas las razones de primer orden aplicables al caso. Puede considerar que el compromiso que refleja la regla que prohíbe los aparatos de radio -la tranquilidad de los usuarios prevalece frente al deseo de oír la radio- es plenamente válido y, por lo tanto, permanece sin derrotar, no obstante lo cual, estos supuestos quedan fuera del alcance de la regla o constituyen una excepción a la misma. En suma, en estos supuestos, la derrotabilidad se predica de la prescripción contenida en la formulación normativa mediante la que la regla se expresa, pero no del balance de razones subyacentes a la misma.

Centrándonos en el Derecho, podríamos señalar que los jueces y demás aplicadores del Derecho pueden considerar derrotada una regla, en primer término, cuando el resultado al que llevaría aplicar una regla con autonomía semántica - prohibido aparatos de radio en la biblioteca- no se compadece 
bien con el compromiso entre razones de primer orden expresado en la regla -la tranquilidad de los usuarios prevalece frente al deseo de oír la radio-. Esta falta de adecuación se pondría de manifiesto, singularmente, en los casos de excepción a las reglas, en los que falta alguna consideración en el balance de razones de primer orden y en los casos que quedan fuera del alcance de las reglas.

Ahora bien, si hemos distinguido entre prescripciones contenidas en la formulación normativa de las reglas, de un lado, y justificaciones subyacentes a las mismas, de otro, tiene sentido hablar de derrotabilidad en ambos niveles. Es posible que lo que se derrote sea -como en los ejemplos anteriores- la prescripción contenida en la formulación normativa -prohibidos los aparatos de radio en la biblioteca-, pero también cabe la derrotabilidad de los compromisos (o juicios de prevalencia) entre razones subyacentes a las reglas. De manera que es posible también que, en segundo término, de forma excepcional, los jueces y demás aplicadores del Derecho consideren derrotada una regla cuando estimen que el compromiso entre razones que subyace a la formulación normativa está mal construido. Tal cosa sucede cuando, a la luz de otros compromisos o juicios de prevalencia entre razones, que se hallan implícitos o explícitos en otras partes del sistema jurídico y que son aplicables al caso en cuestión, se aprecia un error en el propio compromiso entre razones de primer orden que opera como justificación subyacente de la regla. Lo característico de esta derrotabilidad en el nivel de las justificaciones subyacentes a las reglas, frente a las derrotabilidad en el de las prescripciones contenidas en las formulaciones normativas, es que la regla fracasa, tanto en este caso como en casos sucesivos, como razón protegida. No se trata, como en los ejemplos anteriores, de problemas producidos por el carácter supraincluyente de la prescripción contenida en la formulación normativa, que en nada cuestionan el juicio de prevalencia entre razones de primer orden que opera como justificación subyacente de la regla; lo que se refuta por erróneo es el propio juicio de prevalencia que opera como razón subyacente de la regla, por lo que se asume que ésta no debe jugar ningún papel en la toma de decisiones futuras ${ }^{19}$.

Abundando en esta idea, podríamos añadir que, mientras lo que se cuestiona en el primer tipo de supuestos es la aplicabilidad de la prescripción al caso concreto, en el segundo es su validez. De manera que, mientras en el

${ }^{19}$ En Razonamiento judicial y reglas hablaba de errores de primer grado y errores de segundo grado para referirme a dos tipos de errores, correlativos a las dos formas de derrotabilidad de las reglas a las que acabo de referirme, que cometerían los jueces que aplicaran estas reglas[cfr. ob. cit., págs. 77 y sig.]. Los errores de primer grado están vinculados a la derrotabilidad en el nivel de las formulaciones normativas, mientras que los errores de segundo grado van vinculados a la derrotabilidad en el nivel de las justificaciones subyacentes a las reglas. 
primer caso decimos que la norma queda desplazada, en segundo nos referimos a su nulidad. Por cierto, en sistemas jurídicos como el nuestro, de control de constitucionalidad concentrado, no está previsto que los jueces ordinarios declaren la nulidad de una regla (de rango legal), sino que suspendan la aplicación de la regla y planteen una cuestión de inconstitucionalidad. En los sistemas de control de constitucionalidad difuso, por el contrario, es el propio órgano de aplicación el que debe desarrollar una argumentación que demuestre que el sistema jurídico contiene otro juicio de prevalencia de las razones aplicables al caso que es opuesto al que opera como razón subyacente a la regla y que es aquél el que debe prevalecer.

Ahora bien, salvo algunos supuestos a los que me referiré al final de este apartado, admitir la derrotabilidad de las formulaciones normativas, así como de las justificación subyacentes a las reglas, no supone sin más negar que el Derecho determine positivamente la conducta de los jueces. Como acabamos de ver, un juez puede dejar de lado una regla cuando considere que un supuesto está fuera de su alcance, o constituye una excepción a la misma. Pero los aplicadores del Derecho no son libres de formular cuantas excepciones o exclusiones del alcance de las normas deseen y cuando lo deseen. El aplicador del Derecho tiene que demostrar que, a la luz del sistema de principios que dotan de sentido a la institución o sector normativo en cuestión, el caso en discusión constituye una excepción o está excluido del alcance de la regla.

Tampoco es libre el juez a la hora de apreciar la derrotabilidad de las justificaciones subyacentes a las reglas ${ }^{20}$. Para empezar, un juez no puede rechazar por erróneo el compromiso entre razones contenido en una norma jurídica aplicable basándose en razones hasta el momento no reconocidas por el ordenamiento jurídico. Por ejemplo, no puede apelar simplemente a la consecución de los intereses de ciertos grupos sociales, a la realización de programas políticos, a la potenciación de nuevos objetivos sociales o a la promoción de nuevos valores no incorporados hasta el momento al orden jurídico. Razones como éstas sólo pueden ser alegadas por el legislador para justificar la aprobación de una regla que incorpore un nuevo compromiso entre razones de primer orden, o la derogación de un regla que contenga un compromiso que se estime inadecuado, pero nunca pueden ser esgrimidas por los órganos de aplicación.

Además, los jueces tampoco pueden componer a su arbitrio un nuevo compromiso entre las razones de primer orden contenidas en las reglas. Este es el error en el que incurre el particularismo sensible a las reglas cuan-

\footnotetext{
${ }^{20}$ Sigo de cerca las consideraciones expresadas por J. Aguiló en «Independencia e imparcialidad de los jueces y argumentación jurídica», Isonomía, México, núm. 6, pág. 75.
} 
do estima que el operador jurídico que decide dejar de lado una regla es libre de componer, con las razones de primer orden contenidas en las mismas, el balance que estime oportuno. En contra de lo que supone el particularismo sensible a las reglas, los jueces sólo pueden dejar de lado las reglas oponiendo la prevalencia de otros compromisos entre las razones de primer orden aplicables al caso en cuestión que ya figuran expresa o tácitamente en el sistema.

En suma, tanto en el caso de la derrotabilidad de las prescripciones contenidas en las formulaciones normativas, como en el de las justificación subyacentes a las reglas, para poder dejar de lado una regla en principio aplicable el juez tiene que basarse en el sistema de principios que dotan de coherencia a la institución o sector normativo de que se trate. Por lo tanto, tiene que aludir a razones que guardan una estrecha relación con las ideas de coherencia normativa o congruencia. Ahora bien, pese a lo que llevo dicho, todavía cabe concebir algún supuesto excepcional en el que el órgano jurisdiccional quede exonerado de esta obligación de sometimiento al Derecho. De tales supuestos excepcionales paso a ocuparme en las próximas líneas, al hilo de la tercera noción de derrotabilidad que nos queda por explorar.

Hasta aquí me he ocupado de dos nociones de derrotabilidad asociada a las reglas, en tanto que razones que se integran en el razonamiento judicial, bien se trate de lo que he llamado derrotabilidad en el nivel de las prescripciones contenidas en las formulaciones normativas, bien de lo que denomino derrotabilidad en el nivel de las justificaciones subyacentes a las reglas. Aunque mi intención al diferenciar entre distintas acepciones de derrotabilidad no es establecer una clasificación exhaustiva y excluyente, todavía sería posible afinar algo más y distinguir, como he señalado hace unas líneas, una tercera acepción de derrotabilidad, según la cual hablaríamos de derrotabilidad cuando, de acuerdo con el Derecho, concurren razones para basar la respuesta a un problema de indeterminación en criterios extrajurídicos, es decir, criterios ajenos a los que el propio Derecho establece; y no basados, por lo tanto, en creencias compartidas en la comunidad jurídica. Esta tercera noción de derrotabilidad, a la que me voy a referir en lo sucesivo con la expresión derrotabilidad radical de las normas jurídicas, ha sido minuciosamente perfilada por Juan Carlos Bayón en un reciente traba$\mathrm{jo}^{21}$. Este autor sostiene la derrotabilidad de las normas mismas como un hipotético resultado al que sería posible llegar cuando se completa el proceso de identificación del Derecho que se desarrolla tomando en cuenta no sólo

\footnotetext{
${ }^{21}$ Juan Carlos Bayón, «Derrotabilidad, Indeterminación del Derecho y positivismo jurídico», Isonomía, núm. 13, México, octubre de 2000, págs. 87 a 117.
} 
con las convenciones semánticas imperantes, sino también las interpretativas. $^{22}$

Bayón, partiendo de un trabajo previo de Rodríguez y Sauca, pero separándose de la tesis mantenida por estos dos autores, defiende que la presencia en el Derecho de normas derrotables en esta tercera acepción es contingente. Dicho en forma muy sumaria, pues me resulta imposible abordar aquí con mayor profundidad la cuestión, Bayón sostiene que la derrotabilidad en esta tercera acepción dependería de dos variables ${ }^{23}$ : La primera de estas variables sería la existencia o no en el Derecho de reglas de clausura respecto de la relevancia. Dichas reglas consistirían en una prescripción de considerar el conjunto de propiedades relevantes obtenido al final del proceso de identificación de las normas como condiciones suficientes de las calificaciones normativas correspondientes, o, lo que es lo mismo, de considerar irrelevantes cualesquiera propiedades distintas de ellas ${ }^{24}$. Pues bien, Bayón defiende que es una cuestión de hecho la presencia o no en el Derecho de una convención interpretativa -aplicable a una, varias o todas las normas del sistema- que establezca una regla de clausura respecto de la relevancia. De manera que puede darse el caso de que las convenciones interpretativas no incluyan -en relación con una, varias o todas las normas del sistema- una regla de clausura semejante; de ahí que podamos afirmar que una norma es derrotable cuando de hecho no existe en relación con ella una regla de clausura respecto a la relevancia. En palabras de Bayón «ello querría decir que la norma se acepta como una mera regla de la experiencia [ rule of thumb], lo que indica que solamente a partir de ella no es posible derivar ninguna solución concreta respecto de ningún caso particular, puesto que para llegar a establecerla siempre será necesaria una evaluación, que por hipótesis no estaría guiada por criterio alguno proporcionado por el propio sistema normativo, acerca de la relevancia o irrelevancia de cualesquiera propiedades del caso concreto distintas de las que definen el supuesto de hecho de la norma derrotable. Si esta conclusión es correcta -prosigue Bayón- cabría afirmar que una norma jurídica genuinamente derrotable deja el Derecho indeterminado en lo que concierne a los casos subsumibles en su supuesto de hecho. De manera que la resolución de cualesquiera de éstos requiere siempre una decisión discrecional entre alternativas abiertas por parte del aplicador» ${ }^{25}$.

\footnotetext{
${ }^{22}$ Cfr. ob. cit., pág. 103.

23 Cfr. ob. cit., pág. 109

${ }^{24}$ Cfr. ob. cit., pág. 104.

${ }^{25}$ Cfr. Ob cit, págs. 104 a 105.
} 
La segunda variable de la que dependería la derrotabilidad en esta tercera acepción sería la existencia o no en el Derecho de relaciones de preferencia preestablecidas para el caso de colisión entre dos normas. Nuevamente aquí sostiene Bayón que es una cuestión contingente la presencia de normas cuya relación de preferencia no esté, de acuerdo con las convenciones interpretativas existentes, preestablecida en relación con algunas de las demás normas del sistema ${ }^{26}$. «Podría pensarse -señala Bayón- que el producto final del proceso de identificación del Derecho sólo será un conjunto de normas inderrotables cuando el sistema contenga una ordenación completa de todas ellas; y que por el contrario, cuando tal ordenación completa no exista, el sistema contendría tanto normas inderrotables (aquellas cuya relación de preferencia en caso de colisión esté preestablecida en relación con todas las restantes) como normas derrotables (aquellas otras cuya relación de preferencia no esté preestablecida en relación con alguna o alguna de las normas del sistema)» ${ }^{27}$.

\footnotetext{
Ahora bien, como el propio Bayón advierte, esta conclusión no es aceptada por Rodríguez y Sucar. Lo que éstos autores sostienen es, por el contrario, que tanto cuando existe una regla de clausura respecto de la relevancia, como cuando no existe, el sistema «correlaciona inderrotablemente ciertas soluciones a ciertos casos», con la diferencia de que en el segundo de los supuestos los jueces estarían habilitados para cambiar el Derecho, que, en su opinión, sería exactamente lo que estarían haciendo cada vez que decidieran considerar relevante alguna propiedad distinta de las que configuran el supuesto de hecho de las normas preexistentes.

A su vez, Bayón se opone a esta tesis señalando que afirmar que el sistema «correlaciona inderrotablemente ciertas soluciones a ciertos casos» implica decir que especifica condiciones suficientes para el surgimiento de las condiciones normativas establecidas. Pero, a juicio de Bayón, no hay propiedades que puedan operar como genuinas condiciones suficientes cuando no es obligado considerar como irrelevantes cualesquiera propiedades diferentes (que es exactamente lo que implica decir que no existe una regla de clausura respecto a la relevancia). «La solución de Rodríguez y Sucar, por lo tanto, -prosigue Bayón- borraría la diferencia entre una situación en la que el Derecho establece genuinas condiciones suficientes de las calificaciones normativas correspondientes (que - siendo el Derecho un sistema dinámico- obviamente pueden ser modificadas en el futuro por las autoridades normativas a las que el sistema atribuya competencia para hacerlo), y otra en la que el proceso de identificación del Derecho no pueda cerrarse con el aislamiento de un conjunto de propiedades que quepa considerar genuinas condiciones suficientes de las soluciones normativas establecidas» [Ob. cit., págs. 105 a 106]. A mi juicio este último argumento esgrimido por Bayón es decisivo. Diferenciar conceptualmente entre situaciones en las que el Derecho establece genuinas condiciones suficientes de las calificaciones normativas correspondientes y situaciones en las que tales condiciones no quedan aisladas, permite subsumir los dos primeros sentidos de derrotabilidad de los que me he ocupado -derrotabilidad de las prescripciones contenidas en las formulaciones normativas y derrotabilidad del balance de razones subyacente a las formulaciones- en las situaciónes del primer tipo ya que en estos casos, como acabamos de ver, el Derecho todavía proporciona criterios en los que basar la respuesta. En cambio, la noción de derrotabilidad radical quedaría reservada para el segundo tipo de situaciones.

${ }^{26}$ Cfr. ob. cit., pág. 109.

${ }^{27}$ Conviene advertir que nuevamente Rodríguez y Sucar rechazan esta segunda posibilidad de admitir que pueda haber normas jurídicas derrotables. Para estos autores, cuando no es-
} 
En todo caso, como el propio Bayón admite, la derrotabilidad en esta tercera acepción «constituye un fenómeno con menor relevancia en nuestras prácticas jurídicas reales que la que a veces se le atribuye» ${ }^{28}$. De hecho creo que el objeto de su trabajo se encamina más bien a mostrar la posibilidad teórica del fenómeno que su importancia práctica. De ahí que las dos primeras acepciones de derrotabilidad de las que me he ocupado me parezcan más útiles a la hora de reconstruir no sólo el uso que del término hacen los teóricos del Derecho, sino, sobre todo, la forma en la que operan los aplicadores del Derecho cuando resuelven las disputas, así como la actividad que desarrolla la dogmática jurídica y que solemos englobar bajo el impreciso nombre de método jurídico.

\section{Actividad interpretativa y creación discrecional de Derecho}

Como señalaba al comienzo de este trabajo, mi intención es proyectar el análisis precedente, dedicado a las diversas acepciones de los términos indeterminación y derrotabilidad, sobre la actividad aplicativa de normas, con el fin de deslindar los supuestos de indeterminación en los que el Derecho requiere la entrada en juego de la actividad interpretativa de aquellos otros en los que no cabe sino la creación discrecional de normas. Así pues, comenzando por la actividad interpretativa, podemos afirmar que ésta estaría encaminada a la resolución de la indeterminación del Derecho asociada tanto a problemas de tipo lingüístico, como a problemas de coherencia o congruencia normativa. Ahora bien, cuando la indeterminación del contenido del Derecho se basa en problemas de coherencia o congruencia normativa, la actividad interpretativa sólo puede resolver los problemas de derrotabilidad de las normas en las dos primeras acepciones que hemos visto -derrotabilidad de las prescripciones contenidas en las formulaciones normativas y derrotabilidad del balance de razones subyacente- y no, como es obvio, los problemas de derrotabilidad radical. Para la resolución de los problemas de indeterminación lingüísticos y de coherencia normativa se hace necesario recurrir a las convenciones establecidas. Dichas convenciones in-

tán predeterminadas relaciones de preferencia entre dos normas que pueden colisionar, éstas no son «derrotables», sino simplemente contradictorias. Bayón combate esta tesis señalando -a mi juicio acertadamente- que de contradicción en sentido estricto sólo se puede hablar cuando colisionan dos normas que previamente hemos caracterizado como inderrotables, es decir, «cuando se verifican a la vez los antecedentes de ambas y consideramos cada uno de ellos como genuina condición suficiente de soluciones normativas incompatibles. Esta situación puede ser caracterizada también como un conflicto de deberes concluyentes. En cambio, cuando se verifican simultáneamente los antecedentes de dos normas, ninguno de los cuales es considerado como condición suficiente de las correspondientes soluciones normativas, lo que se produce es un conflicto de deberes prima facie» [Cfr. Ob. cit., págs. 107 a 108].

${ }^{28}$ Cfr. ob. cit., pág. 109. 
cluirían no sólo pautas o reglas de tipo semántico, sino también pautas o reglas interpretativas (como puedan ser, en nuestro contexto jurídico, el llamado «instrumento teleológico», el «histórico-evolutivo», etc). Ahora bien, la mayor o menor extensión que se de a estas reglas o pautas interpretativas depende, en buena medida de la concepción del Derecho de la que se parta.

No obstante lo dicho, conviene tener presente que, en sentido lato, también se entiende interpretar como «sistematizar» el Derecho, lo que abarcaría una serie de operaciones distintas, como la integración del Derecho (en presencia de lagunas normativas) y la resolución de antinomias. Ahora bien, como advierte Guastini, aunque la doctrina tradicionalmente engloba estos supuestos como problemas de interpretación, en sentido estricto no lo serían, ya que «las lagunas [las lagunas normativas] y las antinomias son características del sistema jurídico entendido como sistema de normas» y no de las disposiciones jurídicas. Es decir, tanto las lagunas como las antinomias, se presentan -si es que se presentan- cuando ya ha tenido lugar la interpretación ${ }^{29}$.

La discrecionalidad en la aplicación de normas, por su parte, entraría en juego en los casos de indeterminación del Derecho que tienen su origen en la derrotabilidad radical de las normas jurídicas (es decir, en la tercera de las acepciones de derrotabilidad que hemos visto). Si en el caso de la interpretación, las convenciones lingüísticas e interpretativas jugaban -como acabamos de ver- un papel decisivo para la resolución de los problemas de indeterminación, cuando de derrotabilidad radical se trata, dichas convenciones no se aplican. En estos casos podemos entender, siguiendo a Bayón, que concurren razones para apartarse del criterio que el Derecho establece (es decir, convencionalmente determinado) a la luz de criterios que no establece (o sea, no convencionales) y que, por lo tanto sería externos al Derecho. Para dar cuenta de una situación como ésta Bayón propone hablar de convenciones que se autoanulan ${ }^{30}$. Es decir, en ausencia de una regla de clausura respecto de la relevancia, o de normas que preestablecen relaciones de preferencia de acuerdo con las convenciones relevantes, la calificación normativa de una conducta se hace depender de criterios que la totalidad de las convenciones relevantes deja sin seleccionar.

\section{Conclusiones}

Al comienzo de este trabajo señalaba la importancia que tiene, a la hora de analizar los conceptos de indeterminación y de derrotabilidad, tener en

\footnotetext{
${ }^{29}$ Guastini, Riccardo, Le fonti del Diritto e l'interpretazione, ob. cit., págs. 330 y 356.

${ }^{30}$ Cfr. J. C. Bayón, «Derrotabilidad, Indeterminación del Derecho y positivismo jurídico», ob. cit., págs. 112 y 114.
} 
cuenta la conexión existente entre los mismos. El primero de los conceptos que he abordado ha sido el de indeterminación, entendida ésta como una característica que se predica del Derecho. La indeterminación del Derecho puede verse como indeterminación causal de las decisiones judiciales; como defectos lógicos de los sistemas jurídicos (contradicciones y lagunas normativas); como indeterminación debida a imprecisiones lingüísticas (ambigüedad y vaguedad), y, en fin, como indeterminación debida a problemas de coherencia normativa o congruencia. Por su parte, el concepto de derrotabilidad es concebido como una característica que se predica de las normas jurídicas. Esta característica de las normas está vinculada precisamente a la indeterminación debida a problemas de coherencia normativa o congruencia. Para dar cuenta de los problemas que plantea la derrotabilidad de las normas jurídicas he traído a colación la noción de razón protegida para la acción, lo que me ha llevado a detenerme por un momento en algunas nociones procedentes de la teoría de las razones para la acción. De todo este análisis se derivaban dos nociones diferentes de derrotabilidad: la derrotabilidad de las prescripciones contenidas en las formulaciones normativas mediante las que se expresan las reglas y la derrotabilidad del balance de razones subyacente a las mismas. Pero, además, quedaría una tercera acepción de derrotabilidad, según la cual hablaríamos de derrotabilidad cuando, de acuerdo con el Derecho, concurren razones para basar la respuesta a un problema de indeterminación en criterios extrajurídicos, es decir, criterios ajenos a los que él propio Derecho establece; y no basados, por lo tanto, en creencias compartidas en la comunidad jurídica. A esta tercera acepción me he referido como derrotabilidad radical de las normas jurídicas.

Finalmente, el análisis de los conceptos de indeterminación y de derrotabilidad me ha abonado el terreno para ocuparme de dos aspectos fundamentales en la aplicación judicial del Derecho: la actividad interpretativa y la discrecionalidad. Respecto la actividad interpretativa, he señalado que el proceso interpretativo está encaminado a resolver los problemas de indeterminación del Derecho debidos a imprecisiones lingüísticas y a dificultades de coherencia normativa o congruencia. Estos últimos a excepción, claro está, de los supuestos de derrotabilidad radical de las normas jurídicas, para los que ni las convenciones lingüísticas ni las interpretativas ofrecen soluciones. Con respecto a la discrecionalidad, he señalado que entraría en juego en aquellos casos en los que la indeterminación del Derecho se debe a problemas de derrotabilidad radical de las normas jurídicas. Como ya adelantaba al comienzo de este trabajo, en mi opinión, una reconstrucción adecuada de la tarea de aplicación de normas que llevan a cabo los jueces debe tratar de dar cuenta del punto de inflexión en el que el Derecho requiere el paso de la actividad interpretativa a la creación discrecional. Confío en 
haber sido capaz, a lo largo de estas páginas, de arrojar alguna luz sobre dicho punto de inflexión.

\section{Bibliografía}

Aguiló, Josep, «Independencia e imparcialidad de los jueces y argumentación jurídica», Isonomía, México, núm. 6, págs. 71 a 79.

- Teoría general de las fuentes del Derecho (y del orden jurídico), Ariel, Barcelona, 2000.

Alchourrón, Carlos y Bulygin, Eugenio, Introducción a la metodología de las ciencias jurídicas y sociales, Astrea, Buenos Aires, 1974.

Atienza, Manuel y Ruiz Manero, Juan, Las piezas del Derecho. Teoría de los enunciados jurídicos, Ariel, Barcelona, 1996.

- Ilícitos atípicos, Trotta, Madrid, 2000.

BAYÓn Mohíno, Juan Carlos, «Sobre la racionalidad de dictar y seguir reglas», Doxa. Cuadernos de Filosofía del Derecho, Alicante, núm. 19, 1997, págs. 143 a 180.

- «Derrotabilidad, Indeterminación del Derecho y positivismo jurídico», Isonomía, núm. 13, México, Octubre de 2000, págs. 87 a 117.

Dworkin, Ronald, A matter of principle, Harvard University Press, Cambridge, 1985.

- Law's Empire, Belknap Press, Harvard, 1986.

- Los derechos en serio, trad. de Marta Guastavino, Ariel, Barcelona, 1989.

GuASTINI, Riccardo, Le fonti del Diritto e l'interpretazione, Giufrè, Milán, 1993.

LIFANTE VIDAL, Isabel, «Sobre el concepto de discrecionalidad jurídica», cito por el original policopiado.

RAZ, Joseph, Razón práctica y normas, trad. de Juan Ruiz Manero, Centro de Estudios Constitucionales, Madrid, 1991.

- «¿Por qué interpretar?», Isonomía, núm. 5, 1996, págs. 25 a 40.

Redondo, $\mathrm{M}^{\mathrm{a}}$ Cristina, «Teorías del Derecho e indeterminación normativa, Doxa. Cuadernos de Filosofía del Derecho, Alicante, núm. 20, 1997.

RóDENAS, Angeles, Razonamiento judicial y reglas, Fontamara, México D.F, 2000.

RodríGuEZ, Jorge Luis, «La derrotabilidad de las normas jurídicas», Isonomía, México, núm 2, 1997, págs. 149 a 167.

RodríGuEZ, Jorge Luis y SuCAR, G., «Las trampas de la derrotabilidad. Niveles de análisis de la indeterminación del Derecho», Doxa, Alicante, núm. 21, vol II, 1998, págs. 403 a 420.

RodRíGUEZ, Jorge Luis, «Lagunas axiológicas y relevancia normativa», Doxa. Cuadernos de filosofía del Derecho, Alicante, 1999, núm. 22, págs. 349 a 369.

SCHAUER, Frederick, Playing by the Rules. A Philosophical Examination of Rule-Based Decision-Making in Law and Life, Clarendon Press, Oxford, 1991. 
$\triangle \quad$ DOXA 24 (2001) 